\title{
Korean College Students' Attitudes toward Disability and Inclusive Education: Latent Profile Analysis
}

\author{
Yun-Jeong Shin ${ }^{1} \cdot$ Eun $\mathrm{Ji}^{2}$ · Soyoung Park
}

Accepted: 31 January 2022

(c) The Author(s) 2022

\begin{abstract}
The purpose of this study was to explore the differences in cognitive-behavioral attitudes and emotional connectedness toward people with disabilities (PWDs) and the attitudes toward inclusive education. In total, 309 college students from various universities in South Korea aged from 18 to 29 years (177 male and 130 female) voluntarily participated in this study. The participants were completed a set of questionnaires: Social Distance Toward Disabilities scale, Interaction with Disabled Person Scale, and Teachers' Attitudes toward Inclusive Education Scale. Latent profile analysis (LPA) was used to model four distinct types: distant (3.56\%), lukewarm (73.91\%), rationalizing (8.41\%), and potential proactive (14.12\%). The majority of participants were lukewarm type who had a slightly cognitive-behavioral distance with mediocre empathy toward PWDs, which links to vague stands toward inclusive education. Potential proactive type, the second largest group, showed a positive attitude toward inclusive education with a high level of empathy but still had ambivalent perceptions toward PWDs. The rationalizing and distant groups had one thing in common that they had a relatively low level of empathy toward PWDs, but showed a markedly opposite position in inclusive education. The findings indicate that interventions should be tailored based on the type-specific attitudes and experiences with PWDs in public and educational settings.
\end{abstract}

Keywords Cognitive-behavioral attitudes · Emotional connectedness · Inclusive education · People with disabilities · Korean college students $\cdot$ Latent profile analysis

\section{Introduction}

With a focus on accessibility and advocacy, the topic of how psychology can better serve the people with disabilities (PWDs) has been addressed in several conventions since 1970s which later led to the launch of the Committee on Disability Issues (American Psychological Association, 2012). The conceptualization of disabilities can vary based

Eun Ji

eji@inha.ac.kr

Yun-Jeong Shin

yj.shin@snu.ac.kr

Soyoung Park

soyoung.park@wku.edu

1 Department of Education, Seoul National University, 1 Kwanak-roKwanak-gu, Seoul, Republic of Korea

2 School of Education, Inha University, Inha-ro 100, Mitsuhol-gu, Incheon, Republic of Korea

3 Department of Special Education, Western Kentucky University, Bowling Green, KY, USA on the area where the disability is defined, but according to the Americans with Disabilities Act (ADA, 1990), these can include individuals with physical or mental impartment(s) that substantially limit one or major life activities. As the psychology devoted to understand emotion, cognition, and behavior of human with emphasis on multiculturalism and social justice(Gelso et al., 2014; Hailes et al., 2021; Sue \& Sue, 2003), studies on minority identity issues, such asrace/ ethnicity and sexual and gender minority, were well-developed, while issues related to disability or ableism have been rarely dealt with in the psychology field, academically or practically (Foley-Nicpon\& Lee, 2012; Woo et al., 2019). Able-bodied privilege, which refers to the unearned privilege held by individuals without disabilities. can be expressed via their attitudes toward PWDs and inclusive education.

Inclusive education refers to the transformational process of constant improvement within schools and education system to provide welcoming and participatory learning experiences for all students, irrespective of the range of abilities or disabilities (UNESCO, 2016). For example, if an individual reported explicitly to have positive attitudes toward disability 
and inclusive education that are out of pity, sympathy or political correctness, the reported positive attitudes could be considered a reflection of subtle discrimination toward PWDs rather than a reflection of deepened understanding of diversity and mutual reciprocity due to inclusive education. However, within the counseling psychology field, there are a dearth of studies about individuals' perceived social distance toward disability, whether there are differences in their attitudes toward disability and related institutional policies, and the impact on their daily lives.

Considering that overt discrimination or prejudicial attitudes are currently deemed inappropriate, individuals are not likely to explicitly reveal their personal attitudes and feelings, particularly if their personal experiences with PWDs and inclusive education are not pleasant. Thus, some people are likely to support affirmative actions or diversity inclusive policies or plans, such as inclusive education, even though they lack empathy or positive attitudes toward PWDs on the basis of their personal interaction experiences. Regarding these different types of attitudes, Wrightsman and Brigham (1973) coined the term "societal attitudes," which refers to prevailing beliefs influenced by cultural orientation, historical background, or other environmental conditions that could differ from personal attitudes. Societal attitudes are considered to be driven by one's intention to be consistent with his/her peers, and they fit into certain environments or are the reflection of a desire to be politically correct (PC). In other words, one's societal attitudes might not always be congruent with his/her personal attitudes, which are more private internal reactions and feelings.

Thus, due to the need to appear PC, students without disabilities might explicitly insist that they have positive attitudes toward inclusive education, even if they have ambivalent or even negative feelings toward PWDs. The pressure to appear PC may have huge implications on individuals' social lives and people are likely to not want to be perceived as culturally insensitive. Given the perceived social pressure and desire to be accepted, people are likely to overtly support PC issues, such as support for affirmative action, despite privately-held doubts or uncertainties. Being PC is not equal to acceptance of diversity and is even worse than explicit discrimination, because it undervalues human variety, closes individual minds to opportunities to understand and discuss differences, and drives people into separate and hostile environments (Sue, 1999).

Thus, the present study focused on exploring the possible heterogeneity in the attitudes toward PWDs and related educational policies with respect to inclusive education among college students. This study specifically investigated whether we can categorize people based on the differences in their cognitive-behavioral attitudes and emotional connectedness toward PWDs, as well as their overall attitude toward inclusive education. Considering that counseling psychology is recognized for its emphasis on prevention, having a better understanding of the possible differences in attitudes toward PWDs would be helpful in preventing any form of harassment and discrimination toward PWDs, both on campus and in larger society.

\section{Disability and Inclusive Education}

Individuals with disabilities comprise one of the largest marginalized and underrepresented groups in the world. In fact, approximately $15 \%$ of the world's population live with at least one disability (World Health Organization, 2015). Therefore, major international organizations (e.g., United Nations, UNESCO) and many countries (e.g., Brazil, China, Republic of Korea, United States) identified the concept of disability and clarified disability rights (e.g., workforce, employment, community settings, etc.) and special education rights through declarations, guidelines and legislation. In the case of the United States, the Americans with Disabilities Act (ADA) of 1990 and the Individuals with Disabilities Education Act(IDEA) of 1997 were enacted (Code of Federal Regulations, 2008). These two pieces of legislation are considered to be the most significant in establishing the concept that all individuals with disabilities should be protected from discrimination in job-seeking/employment and community settings and educated in an inclusive and responsive education setting (Friend \& Bursuck, 2002; Szymanski \& Parker, 2003)

Education gives the context for each person's relationship with people, society, community, culture, system, etc. In addition, education helps each person develop and gain an independent identity through the whole life. Therefore, education is also important and essential to assist PWDs to deal with various challenges in their workplace, daily lives and community (Fuchs \& Fuchs, 1994; Mittler, 2012; Szymanski \& Parker, 2003). Based on this notion above, the inclusive education movement is rooted in the belief that every student within the full spectrum of diversity should be fully integrated into general education environments, and that their education should be conducted based on their abilities and the possibilities of overcoming their limitations (Will, 1986). Inclusive education includes the premises of reconstruction of mainstream school systems, such that every school accommodates students with disabilities, rather than as similates students with disabilities into an unchanged mainstream school environment that is targeted to the needs of general students (Fuchs \& Fuchs, 1994; Will, 1986). Thus, inclusive education requires that policymakers and educators make appropriate accommodations (Villa et al., 1996). The successful implementation of inclusive education policies is largely dependent on general populations (general education teachers, peers, and parents). Thus, the 
issues of being positive and active about inclusive education (Fuchs \& Fuchs, 1994) and understanding the perceptions of individuals without disabilities toward inclusive education and individuals with disabilities must be addressed. However, previous studies around the world have only generally addressed the perspectives about inclusive education among general populations or investigated the struggles experienced by students with disabilities, educators, and parents under inclusive educational settings. Instead, there is a lack of studies regarding detailed and categorized features of the thoughts, perceptions, and experiences about disability issues and inclusive education among the general population (Amor et al., 2019; De Boer et al., 2011; Ferguson, 2008). Therefore, it is essential to explore detailed and live features surrounding inclusive education, and it enables PWDs to feel like to be part of their community, gain their own independent identy and stay in good mental health.

\section{Attitudes Toward Disabilities and Inclusive Education}

To understand thoughts, ideas, and perceptions toward inclusive education among the general populations, attitudes could be one of the adequate terms representing various concepts mentioned above. Attitudes are generally defined as an evaluation of an object, including people, groups, things, and ideas (Bohner \& Dickel, 2011). However, regarding stability in a person's attitudes, previous studies revealed a variety of ideas. Supporters of the stable-entity model believe that attitudes are stable entities with summary evaluations that are stored in the memory (Fazio, 2007; Visser $\&$ Mirabile, 2004). In contrast, other researchers, such as Gawronski and Bodenhausen (2007) and Conrey and Smith (2007), posited that attitudes are time-dependent evaluative judgments that are studied mainly in the consumer or personnel psychology literature. The current study is based on the stable-entity model (Fazio, 2007; Visser \& Mirrabile, 2004) with the assumption that attitudes, as stable entities in the memory, are closely related to cognitive-behavioral approaches, wherein behaviors are strongly influenced by cognition-implying attitudes.

To understand human attitudes, researchers have suggested several theories. Among these, the ABC model of human disturbance (Beck, 1976; Ellis, 1962; Wessler, 1988), the first theory to explain human attitudes, has been constantly modified and criticized. The first supporters of the ABC model, such as Ellis (1962), believed that human disturbances, including arbitrary inference, overgeneralization, magnification/minimization, and dichotomous thinking, are generated by logic or misinterpretations about each individual's experience and formed cognitive schemata. Recent studies on cognitive behavioral model emphasized on the role of emotions in the ABC model (e.g., Bernard, 2009; Ellis, 2006), positing that emotions are intertwined and have an influence on perceiving, judging, reasoning, verifying the logical inferences, deciding, and performing certain behaviors (Li and Lee, 2011; Pham, 2007). Thus, many studies agree that both cognitive understanding and emotions are important in understanding human attitudes toward concepts, things, and events in our society. It means that cognitive-behavioral understanding and emotions could be good indicators to explore attitudes toward inclusive education among the general population.

In the current study, cognitive-behavioral attitudes toward disability refer to evaluative judgments toward disability, leading to a person's action selection. Of several concepts regarding cognitive-behavioral attitudes toward disability, this study applied social distance toward disability as a cognitive-behavioral attitude factor. Social distance is defined as the degree of intimacy and understanding toward objects (Bogardus, 1925; Bogardus, 1933). A high level of social distance, in this study, refers to negative evaluative judgments or an unwillingness to interact or engage in activities with PWDs. The degree of social distance could vary from full acceptance of PWDs to the tendency to overtly discriminate against them (Ouellette-Kuntz, Burge, Brown, \& Arsenault, 2010). In case of emotional disturbances, including schizophrenia, general public's patterns of social distance toward PWDs showed differently depending on the perceived success of intervention, individual fears regarding perceived dangerousness, and willingness to interact with PWDs (Grausgruber et al., 2007). Furthermore, previous studies have shown that social acceptance and distance toward peers with disabilities may be formed starting from an early age, and that cooperative-learning programs must be emphasized to prevent social distance toward peers with disabilities among young children (Piercy, et al., 2002). In other words, people tend to show various types of social distance toward PWDs, which were formed at early age and had been kept in each person's perception so long. Thus, the social distance toward disability in this study includes individuals' cognitive perceptions based on their stereotypes or biases toward PWDs, along with their behavioral intentions to avoid interacting with PWDs and to maintain their daily life without managing disability issues.

To understand emotions toward inclusive education among the general population, this study put emotional connectedness as a factor relating to emotions. Emotional connectedness, which is distinct from cognitive-behavioral responses, is defined as an affective response or a sense of relatedness to objects or people (Townsend \& McWhirter, 2005). Previous studies suggest that emotional connectedness affect judgment and decision-making processes (Bechara et al., 1997; Damasio, 1994). The emotional connectedness formed by emotionally informative signals can 
result in action, finally-decisive attitudes, or choices (Nielsen \&Kaszniak, 2006; Winkielman et al., 2005). Thus, measuring emotional connectedness is rooted in the doubt that measuring explicit attitudes, including cognitive-behavioral attitudes, may not fully reveal people's implicit attitudes or feelings (Fazio \& Olson, 2003). Based on previous studies, the current study defined emotional connectedness toward disability as an individual's perceived or experienced feelings toward PWDs. Emotional connectedness can reflect an individual's degree of empathy, sympathy, guiltiness, or confused feelings on the basis of their knowledge, awareness, and skills with respect to how to interact with PWDs. To measure emotional (implicit) feelings toward disability, this study focuses on emotional connectedness on the basis of interaction experiences with PWDs. This is important, as emotional connectedness may vary from cognitive-behavioral attitudes and result in skepticism toward inclusive education practices, even though a person has positive cognitions toward disability and inclusive education. For example, Vilchinsky et al (2010) found that reading about an encounter with a person with disability created more negative emotions than reading about an encounter with a person without a disability, despite adjustments in participants' attachment orientations. They suggested that additional contact with people with disability is needed to regulate and overcome negative emotions toward such people. Forlin (1995) also indicated that teachers who were not involved with the policy of inclusion reported that coping with a child with special education needs (SEN) was equally stressful to coping with a child without disabilities; however, teachers who were currently involved in inclusive education reported more perceived stress in coping with a child with special education needs than in dealing with students without disabilities. Thus, Forlin's findings (1995) indicated that teachers' experiences of a child with special education needs might not automatically promote acceptance of inclusion due to the increased stress teachers experienced. These previous findings suggest that people are likely to have an initial negative emotional response toward PWDs, and that mere exposure or interactions with people might not automatically guarantee a change in these possibly negative feelings. Therefore, to investigate the attitudes toward PWDs and inclusive education, both cognitive-behavioral attitudes and emotional connectedness should be addressed simultaneously, as these two patterns may differ.

\section{Attitudes Toward Disability and Inclusive Education in South Korea}

Specifically, we focused on college students' attitudes and emotions toward disabilities and inclusive education within the Korean cultural context. We believe that Korea's unique cultural background and rapid implementation of inclusive education during several decades may contain different aspects about attitudes toward inclusive education among the general populations from those in other countries. Historically, the United States has been considered to have initiated the modern special education system and American special education has influenced inclusive education in many Asian countries including Korea, China, and Singapore, etc. (Kim et al., 2019). To be specific, inclusive education in Korea was significantly influenced by the Christian missionaries' activities after the Korean War, and the first national special education law was strongly influenced by American Special Education Law, P. L., 94-142 in 1970s. (Kim et al., 2019; The Office of Legislation, 2000). Despite the short history of inclusive education, inclusive education in Korea was rapidly implemented within public educational settings. In 2018 , there were a total of 90,780 students with disabilities, 25,919 of whom $(28.55 \%)$ received special education at special schools, 48,848 (53.8\%) received inclusive education in special classrooms, and 15,595 (17.18\%) were in general classroom settings (Korean Association for Special Education, 2019). In South Korea, the availability of inclusive placement for all students with special needs in the general school setting is limited, so students with developmental disabilities, such as emotional disturbance, intellectual disability, learning disabilities, and autism-spectrum disorders, comprise the majority group who receive education services in special classrooms in general schools (Kim, 2012, 2013). In addition, the major concerns in the implementation of inclusive education in South Korea include the lack of paraprofessionals and classroom aids within the classroom, school principals' lack of understanding of the concept of inclusive education and its implementation, and the deficient training or re-education experiences of the teachers handling these classes (Kim, 2006).

Regardless of the inclusive education movement as part of a broad human rights agenda and an increasing number of students with disabilities who received inclusive education in Korea, attitudes toward PWDs and inclusive education remain mixed among individuals without disabilities (Choi \& Park, 2009; Ji \& Shin, 2015; Oh et al., 2007). Several studies in Korea suggested that the inclusive education experiences of individuals without disabilities have little or even a negative impact on their attitudes toward PWDs (Kim 2016; Kim \& Park, 2008; Kwon \& Park 2012). According to a study of Korean high school students (Kim, 2016), participants reported that individuals without disabilities experienced reverse discrimination, wherein able-bodied students face discrimination within the education setting by receiving insufficiently allocated resources and forcing them to endure the unpredictable/uncontrollable behaviors of their peers with disabilities, as a result of receiving inclusive education, mostly just physical inclusive environment, 
with students with disabilities. In addition, participants who experienced inclusive education reported more negative emotional connectedness and cognitive-behavioral attitudes toward inclusive education and skeptical thoughts on its effects than did those who had no experience with inclusive education. Moving up to secondary school, the negative attitudes toward inclusive education worsened among students without disabilities who experienced inclusive education, which is related to very competitive college admissions in Korea (Kim and Park, 2017; Kim, 2016).

In contrast, opposite research findings have reported that inclusive education experiences led to positive changes in attitudes and feelings toward PWDs (Kim \& Park, 2002; Park 2014; Park \& Park, 2007). Specifically, several factors influenced positive attitudes toward PWDs and inclusive education, such as, having close family members who have a disability and the age of first exposure to inclusive education, among others (Raabe \& Beelmann, 2011; Stephan \& Stephan, 2000; Ko \& Mok, 2013; Jung \& Seo, 2012). As an example, Ko (2005) reported that Korean middle school students reported increased positive feelings and a willingness to interact with PWDs after participating in a disability experience program.

Thus, given the previous research on the relationship between attitudes and behavior, if individuals' attitudes arise from their personal experiences, such attitudes are more likely to guide positive actions. If individuals have previous positive experiences interacting with PWDs, these might facilitate more positive attitudes and empathy toward PWDs (Kim \& Park, 2017; Han, 2019). In addition, if individuals have previous unpleasant experiences interacting with PWDs, this might lead to more negative or ambivalent attitudes toward such people and inclusive education. In addition, very competitive ableism happening in college admission, job application, and involuntary early retirement strongly influences people's mixed feelings, perceptions and behaviors toward inclusive education in Korea (Kim \& Park, 2008; Kim, 2015). In sum, attitudes toward inclusive education among the general population in Korea are likely to vary depending on personal experiences and cultural circumstances related to PWDs and inclusive education.

\section{The Purpose of the Present Study}

The overall aim of this study was to model the heterogeneity of attitudes and feelings toward disability and the accompanying inclusive education system. Specifically, this study focused on comparing the differences in cognitive-behavioral attitudes and emotional connectedness toward PWDs, as well in attitudes toward inclusive education among college students who completed school in the public education system.
To the best of our knowledge, this is the first study to examine college students' categorical attitudes toward the inclusion of students with special educational needsintothe general educational settings. Specifically, we tried to explore the various layers of cognitive-behavior attitudes and emotional relatedness toward PWDs and inclusive education among this group. To address the discrepancy between emotional distance toward disabilities and cognitive-behavioral attitudes toward inclusive education and PWDs, we used latent profile analysis (LPA), which offers an unbiased estimation of potential underlying subgroups in a population based on observed variables (Magidson \& Vermunt, 2004; Muthén \& Asparouhov, 2006). A typology on the attitudes toward PWDs could (a) enhance the understanding about the different attitudes of people without disabilities toward PWDs and inclusive education, and (b) help in the development of tailored interventions to address students' internalized ableism and possible micro-aggression or discrimination due to the discrepancy between their actual experiences and attitudes.

\section{Methodolgy}

\section{Participants}

The participants $(\mathrm{N}=309)$ consisted of $177(57.3 \%)$ men and $130(42.1 \%)$ women, aged 18 to 29 years $(\mathrm{M}=23.5)$. A purposive sampling strategy was applied to gather college student sample at various public research universities. All participants were Korean college students without disabilities, who were registered for the introduction of psychology courses at various universities in Seoul, South Korea. Extra credits were given to students as a compensation for volunteering participation in this research. Only students who showed willingness to participate in research were sent a consent form (hard copy) or a secured link via e-mail that presented a consent form. Participants were asked to complete the set of questionnaires. The education levels were $65(21 \%)$ freshmen/women, 92 (29.8\%) sophomores, 74 (23.9\%) juniors, and 78 (25.3\%) seniors. Among the participants, 181 (58.6\%) majored in the humanities and social sciences, $111(35.9 \%)$ in science and engineering, and 17 $(5.5 \%)$ in art, music, and physical education.

\section{Procedure}

This study was approved by the Institutional Review Board (IRB) from the university with which the first author is affiliated. Korean students from three large universities in Seoul, South Korea were recruited with extra credit options. The surveys were completed by students who provided their consent to participate in the study. We used the Korean versions 
of scales, which were translated, validated, and used in previous studies in South Korea (Ko\&Mok, 2013; Gething, 1991; Choi, 2007).

\section{Instruments}

Cognitive-Behavioral Attitudes toward Disabilities To measure non-disabled college students' perceived explicit cognitive-behavioral attitudes toward disabilities, we used the modified Korean version of the Social Distance Toward Disabilities scale (Ko\&Mok, 2013). Ko and Mok (2013) modified the Korean version of the scale for all ages, which was originally used by Jung and Seo (2012). The scale consisted of 20 items with 5 subscales, which were divided based on different social context levels from individual to environment: (a) national-institutional level, (b) general-daily life, (c) school-colleagues, (d) peers, and (e) family. Each subscale had 4 items; sample items included, "I support the welfare of people with disabilities" (national-institutional level); "I can show the way if the people with disabilities ask me the direction" (general-daily life level); "I do not mind taking a class that is taught by a professor with disabilities" (schoolcolleagues level); "I can share a dormitory with people with disabilities" (peer level); and "I do not mind if my family member gets married to a person with disabilities" (family level). Each scale was rated on 5-point Likert scale where in higher scores indicated greater perceived positive cognitive-behavioral attitudes, such as positive perceptions toward PWDs and a willingness to interact with PWDs within daily life, as well as at the societal level. The scale also showed high reliability and validity, with internal consistency ranging from .90 to .97 (Ko \& Mok, 2013). The alpha coefficient in each subscale ranged from .86 to .94 .

Emotional Connectedness toward PWDs Emotional connectedness toward PWDs was measured by the Interaction with Disabled Person Scale (IDP;Gething, 1994). The instrument was first translated into Koreans by authors, after which the items were reviewed and agreed upon by one professional English-Korean translator and one English instructor who taught English at a Korean university. The final Korean version of the IDP consisted of 20 items scores using a 6-point Likert scale $(1=$ totally disagree, $6=$ totally agree $)$. We used 8 items from the Korean version of the IDP that assessed emotional reactions toward PWDs, given their interactions with PWDs. Sample questions included the following: "I feel worth when I can help the individuals with disabilities who need help" and "I feel more comfortable after talking with people with disabilities about their disability." Higher scores on the IDP indicated more positive emotional responses toward PWDs. The alpha coefficient of the total score was .76 in a study by Iacono et al. (2009). In the current study, the alpha coefficient in each item ranged from .60 to .67.
Attitudes toward Inclusive Education To assess attitudes toward inclusive education and its societal and educational effects, we used the three subscales of Teachers' Attitudes toward Inclusive Education Scale, which was developed and validated by Choi (2007). The original scale consisted of 23 items with 4 subscales that measured (a) general perceptions of inclusive education (7 items), (b) social effects of inclusive education (5 items), (c) educational effects of inclusive education (5 items), and (d) teachers' self-efficacy to guide disabled students (3 items). In the current study, we only used 20 items of the first 3 subscales, except the 3 items from the teacher's self-efficacy to guide disabled students. This is because we are mainly interested in students' perception on inclusive education rather than their retrospection on previous teachers' self-efficacy to guide disable students. Sample items included the following: "Students with disabilities need to have an opportunity to learn in regular classrooms as much as possible" (general perception of inclusive education), "Inclusive education has a positive effect on the emotional development of students with disabilities" (social effects of inclusive education), and "Academic challenges in regular classrooms would initiate and improve the academic achievement of students with disabilities" (educational effects of inclusive education). The responses were scored using a 6-point Likert scale in which higher scores indicated greater positive attitudes toward inclusive education. The internal consistency ranged from .74 to .89 in a past work (Choi, 2007). The alpha coefficient in each subscale ranged from was .79 to .89 .

\section{Data Analysis}

We used LPA to identify the unobservable subgroups of students with similar profiles based on response patterns. LPA is a type of latent variable mixture model that is used to find unobservable subgroups of individuals with different probability distributions (Pastor et al., 2007; Vermunt, \& Magidson, 2002). LPA is also a person-centered approach that assumes the various probabilities of individual responses per observable variables (Jung \& Wickrama, 2008). The data appropriate for LPA are typically assumed to consist of unobservable subgroups of individuals with different probability distributions. Although cluster analysis techniques are commonly used to divide a sample into homogeneous subgroups, LPA offers several advantages over cluster analysis (Pastor et al., 2007; Vermunt $\&$ Magidson, 2002). To determine the sufficient sample size for LPA, previous studies presented sample size recommendations depending on number of items, number of classes, and etc. According as previous research suggested, the recommended sample size in LPA model including over 15 items and 3-4 classes was over 256 (Dziak et al., 2014). Based on this notion, the current study followed 
this suggestion, and confirmed the sample size of 309 . The first step in an LPA is to determine the number of subgroups with well-defined, differentiated profiles (Lubke \& Muthén, 2005; Pastor et al., 2007). In the current study, the number of subgroups was selected based on goodness-offit indexes and tests of statistical significance. To achieve this goal, a series of latent profile models ranging from 1 to 5 classes were conducted using MPlus 7.4 program (Muthén \& Muthén, 2015). Model fit was evaluated using the Lo-Mendell Rubin Likelihood Ratio Test (LMR-LRT) and the Bootstrap Likelihood Ratio Test (BLRT), which can determine the statistical indicators of the number of classes that best fit the data (Lo et al., 2001). Several criteria were used to identify the best fitting model, including Akaike Information Criterion (AIC), Bayesian Information Criteria (BIC), and Sample-size Adjusted BIC (SABIC; Maynard et al., 2012). The mixture missing command was used in all analyses to account for any missing data. To deal with the different measurement scales, T-scores, rather than raw scores, were used in analyses. The raw score from each measurement was converted to a T-score, with a mean of 50 and an SD of 10. Finally, the optimum number of profiles was not predetermined, but was interpreted from the combination of statistical IC (Nylund et al.,2007).

Table 1 Normality of Data. CBA= Cognitive Behavioral Attitudes toward people with disabilities, $\mathrm{EC}=$ Emotional Connectedness toward people with disabilities, $\mathrm{AIE}=$ Attitudes toward inclusive education, $\mathrm{IE}=$ Inclusive education

\begin{tabular}{llllll}
\hline Instrument & Subscale & Mean & SD & Skewness & Kurtosis \\
\hline CBA & $\begin{array}{l}\text { National-institutional } \\
\text { level }\end{array}$ & 2.08 & .57 & .27 & -.06 \\
& $\quad$ General-daily life & 1.58 & .54 & .45 & -.59 \\
& School-colleagues & 1.93 & .68 & .40 & -.29 \\
& Peers & 2.03 & .76 & .31 & -.58 \\
& Family & 3.10 & .84 & -.18 & -.18 \\
EC & - & 3.87 & .75 & -.20 & .99 \\
AIE & General perceptions & 3.72 & .75 & -.12 & -.06 \\
& $\quad$ of IE & & & & \\
& Social effects of IE & 3.60 & .74 & .08 & .10 \\
& Educational effects & 3.64 & .82 & .27 & .75 \\
& of IE & & & & \\
\hline
\end{tabular}

\section{Results}

\section{Normality of Data, Number of Groups and Goodness of Fit}

Before analyzing LPA, the normality of data needs to be reviewed. Table 1 represents normality indexes (mean, standard deviation, skewness, kurtosis) in each instrument's subscales. Table 1 shows that each skewness and kurtosis did not exceed 2 and 4, which satisfy the assumptions of normal distribution (West et al., 1995). LPA was used to investigate the plausibility of 1-, 2-, 3-, and 4-class solutions. Classes were added iteratively to determine the best model fit for the data according to both statistical and interpretive perspectives. The final step in LPA was to use the results of the model to classify cases into the appropriate latent classes. Information criterion indexes, particularly AIC, BIC, and SABIC, are the best options in determining the appropriate number of groups (Berlin et al., 2014). To select the best-fitting model in the current work AIC, BIC, adjusted BIC, and entropy were considered. Table 2 represents these values for each model. Researchers generally begin with models that make sense in relation to the hypothesis, a priori predictions, and substantive findings, as well as goodness-of-fit indexes (McCrae et al., 2006). A model with lower AIC and BIC values is preferred over a model with higher AIC and BIC values (Dziak et al., 2014; McCraeet al., 2006). In the present study, the models with four and five latent classes had lower AIC and adjusted BIC values than the other models, and the LMR-LRT and BLRT were more significant in the model with four latent classes. Thus, the model with four latent classes was retained as the best-fitting model in this study. An analysis of the LPA findings indicated that the 4-class solution was statistically and conceptually the best fitting model. As shown in Table 2 the AIC (6852.360), BIC (6919.561), and SABIC (6862.472) values for the four-class solution were lower, and the log likelihood value was higher than the respective values of all previous solutions $(p<.001)$.
Table 2 Fit Statistics for LPA Models

\begin{tabular}{lllllllllll}
\hline Classes & $A I C$ & BIC & SABIC & LMR & BLRT & 1 & 2 & 3 & 4 & 5 \\
\hline 1-class & 6901.235 & 6923.635 & 6904.605 & na & na & & & & & \\
2-class & 6879.653 & 6916.986 & 6885.270 & 0.1008 & 0.0000 & 16.51 & 83.49 & & & \\
3-class & 6860.352 & 6912.619 & 6868.216 & 0.0125 & 0.0000 & 14.41 & 09.26 & 76.32 & & \\
4-class & $\mathbf{6 8 5 2 . 3 6 0}$ & $\mathbf{6 9 1 9 . 5 6 1}$ & $\mathbf{6 8 6 2 . 4 7 2}$ & $\mathbf{0 . 0 1 1 4}$ & $\mathbf{0 . 0 1 2 8}$ & $\mathbf{0 3 . 5 4}$ & $\mathbf{7 3 . 9 1}$ & $\mathbf{0 8 . 4 1}$ & $\mathbf{1 4 . 1 2}$ & \\
5-class & 6850.901 & 6933.034 & 6863.259 & 0.3443 & 0.3333 & 07.96 & 13.47 & 02.81 & 51.13 & 24.61 \\
\hline
\end{tabular}

Note. Bold indicates best fit. $\mathrm{N}=309$, na $=$ not applicable 


\section{LPA Results}

As shown in Table 2, a model with four latent classes had the lowest AIC and adjusted BIC values and significant LMR and BLRT in comparison to the other models. Thus, the 4-class LPA model was identified as the optimal model based on the goodness-of-fit indices. Table 2 and Fig. 1 present the estimated and observed mean growth curves of the four latent classes, respectively.

As can be seen, Group 1 participants' attitudes and emotions toward PWDs and inclusive education hada valley shape. They seemed to experience the most unpleasant and negative emotional connectedness toward PWDs, but relatively higher cognitive-behavioral attitudes toward PWDs with respect to emotions. In contrast to their negative emotional connectedness (or lack of emotional empathy) toward PWDs, they reported higher favorable attitudes toward inclusive education. This group comprised 11 (3.56\%) participants. The means (M) and standard deviations (SD) of the scores for Group 1were as follows: cognitive-behavioral attitudes $(\mathrm{M}=41.40, \mathrm{SD}=3.43)$, emotional connectedness toward PWDs $(\mathrm{M}=29.51, \mathrm{SD}=3.88)$, and positive attitudes toward inclusive education $(\mathrm{M}=54.88, \mathrm{SD}=2.64)$. This group was named the distant type.

Participants in Group 2 showed average levels of cognitive-behavioral attitudes and emotional connectedness toward PWDs and positive attitudes toward inclusive education. This group comprised 228 (73.91\%) participants. The $\mathrm{M}$ and SD of the scores for Group 2 were as follows: cognitive-behavioral attitudes $(\mathrm{M}=50.95, \mathrm{SD}=0.75)$, emotional feelings toward PWDs( $\mathrm{M}=50.65, \mathrm{SD}=0.66)$, and a positive attitude toward inclusive education $(\mathrm{M}=48.77$, $\mathrm{SD}=0.78$ ). This group was named the lukewarm type.

Participants in Group 3 had the most positive cognitive-behavioral attitudes, but lacked positive emotional connectedness toward PWDs, consistent with the lowest score on attitudes toward inclusive education. This group comprised $26(8.41 \%)$ participants. The M and SD of the scores for Group 3were as follows: cognitive-behavioral attitudes ( $\mathrm{M}=56.55, \mathrm{SD}=2.91)$, emotional connectedness toward PWDs $(\mathrm{M}=42.12, \mathrm{SD}=3.64)$, and positive attitude toward inclusive education $(\mathrm{M}=32.98, \mathrm{SD}=2.30)$. This group was named the rationalizing type.

Participants in Group 4 showed moderate cognitivebehavioral attitudes toward PWDs, but held the highest positive emotional connectedness toward PWDs and inclusive education. This group comprised $44(14.12 \%)$ participants. The $\mathrm{M}$ and SD of the scores for Group 4were as follows: cognitive-behavioral attitudes ( $M=43.29, \mathrm{SD}=1.68)$, emotional connectedness toward PWDs $(\mathrm{M}=56.42, \mathrm{SD}=1.80)$, and positive attitude toward inclusive education $(M=65.36$, $\mathrm{SD}=1.60$ ). This group was named the potential proactive type. In summary, the four groups were named the distant type $(\mathrm{N}=11,3.56 \%)$, lukewarm type $(\mathrm{N}=228,73.91 \%)$, rationalizing type $(\mathrm{N}=26,8.41 \%)$, and potential proactive type $(\mathrm{N}=44,14.12 \%)$.

\section{Discussion}

To gain an in-depth understanding about lay people's perceptions about disabilities and inclusive education, we focused on analyzing their attitudes and emotions toward PWDs and inclusive education in this study. By using LPA, the authors identified four distinct attitude profiles among Korean college students: distant, lukewarm, rationalizing, and potential proactive. We discuss each type separately below with the name and keyword that represents the main character of each type.
Fig. 1 Mean for T scores of the four latent profiles. $\mathrm{CBA}=$ Cognitive Behavioral Attitudes toward people with disabilities, $\mathrm{EC}=$ Emotional Connectedness toward people with disabilities, $\mathrm{AIE}=$ Attitudes toward inclusive education

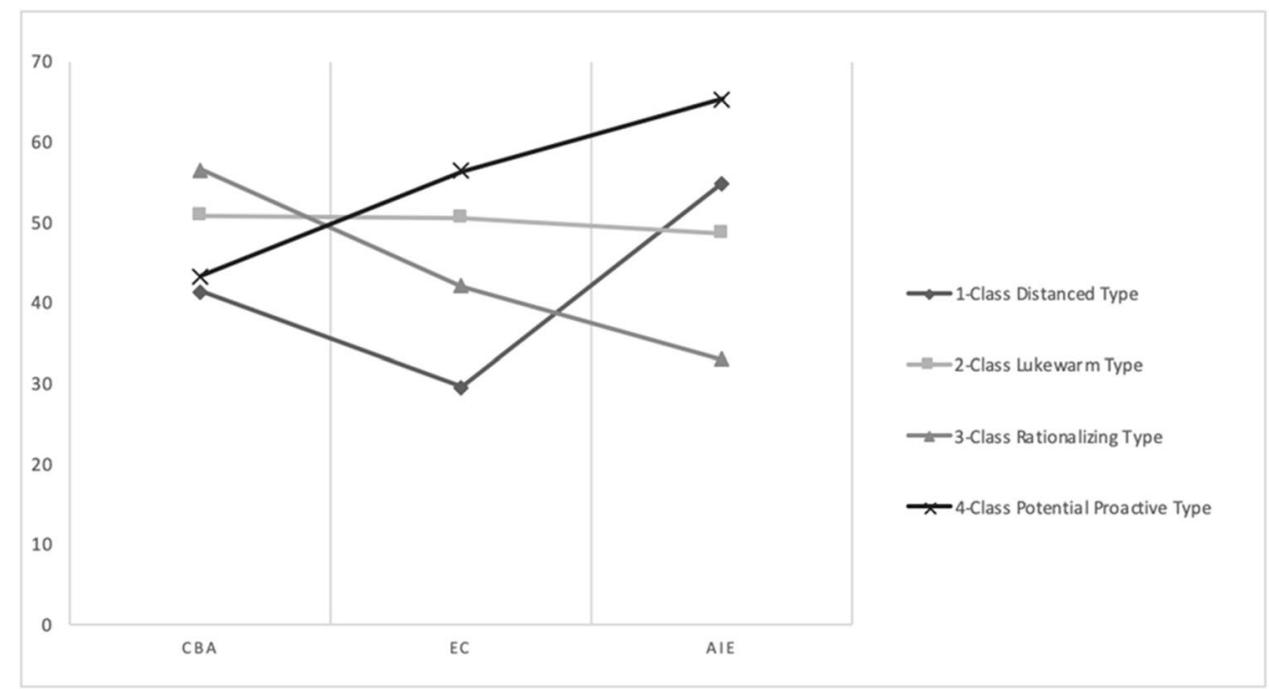




\section{Distant type}

The distant type was the smallest group (3.56\%) and was characterized by negative perceived cognitive-behavioral attitudes toward disabilities. They had the most lack of empathy toward people with disability, but somehow held positive attitudes toward inclusive education. The distant type could be a reflection of the desire to appear politically correct. Individuals in the distant type group were likely to want to avoid being seen as being insensitive culturally (e.g., racist and sexist) and to deny being influenced by stereotypes or prejudices (Hughes, 2011). Thus, even if they might have doubts, fear, or seemed distant toward PWDs, they would still explicitly show their support for affirmative actions or inclusive policies, such as inclusive education, because they desire social support or approval that they are good people.

Regarding processing counter-stereotypic information, individuals may face anxiety when encountering events that affect their social perception and judgment (Wilder \& Shapiro, 1989). Anxiety may lead to unpleasant arousal and stereotype reinforcements or a change in an individual's previous schema. Individuals are likely to deal with anxiety when being asked about or being in contact with out-group (in their knowledge) member or unfamiliar events. The distant type in this study can be interpreted as individuals having a superficial attitude of pursuing a fair society for all while also being reluctant for this to be connected to their personal lives. The phenomenon called "Not In My Back Yard (NIMBY)" could be the result of these limiting attitudes toward disability and PWDs; specifically, such individuals agree that we need to provide equal education opportunity to PWDs, but they do not agree that this should interfere with their personal life (Kamenetsky et al., 2016; Piat, 2000). Thus, they can be considered having more sympathetic or pitiful feelings toward PWDs rather than having more empathetic ones. Hence, they are labeled as the distant type.

\section{Lukewarm type}

The majority of Korean college students in our study were categorized as fitting the lukewarm type profile. This group showed average levels of cognitive-behaviors and emotions toward PWDs. This could mean that these individuals appear to have some mediocre affection toward PWDs with perceived fair to middling cognitive-behavioral attitudes toward PWDs. It seems that they do not actively support inclusive education, which could be seen as indifference in dealing with the disability issues on a daily basis in their personal lives. Considering that more than $70 \%$ of the students participating in the study fell into this group, this implied that students were not likely to recognize the privilege of not having a disability. They were also unlikely to consciously engage in or become familiar with the effect of ableism, i.e., the act of prejudice or discrimination against PWDs and the devaluation of disability (Hehir, 2002).

This tepid tendency can also be explained by the unique Korean cultural stance toward out-group members. Under rapid economic growth in Korea, Koreans try to keep their traditional family- or community-bound culture while assimilating into newly imported cultural stimuli or beliefs; this unique Korean cultural tendency is called compressed modernity (Chang, 2010). As examples of compressed modernity characteristics, some Koreans often agree with inclusive education, embrace immigrant marriages with women from other Asian countries, feminism, or homosexuality issues. At the same time, however many Koreans also feel a sense of reluctance or even try to segregate themselves from those issues. The majority of participants in this study, classified as the lukewarm type, can be better understood within the context of the unique Korean social culture, which has mixed features of accepting new values that embrace diversity and social justice-related issues while showing resistance toward changes as people try to maintain traditional values (e.g., Confucianist ideas).

\section{Rationalizing type}

The rationalizing type consisted of $8.41 \%$ of participants and represented the most positive cognitive-behavioral attitudes toward PWDs and some sense of emotional connectedness toward PWDs. However, they lack of empathy or have uncomfortable feelings toward them as shown by their negative attitudes about inclusive education. This group may represent individuals who remain skeptical or against the principle of inclusive education (i.e., disabled and nondisabled people must receive education together in the real world). Their discriminative behaviors toward inclusive education are likely to be formed due to their past unpleasant experience while interacting with PWDs. For example, current Korean college students represent the generation who experienced the implementation of inclusive education in the secondary educational system; thus, they have first-hand experiences in studying together with peers with disabilities in the same classroom during their middle or high school years (Kim, 2012). At first, they may be naïve or have a slightly favorable image of PWDs; however, as they experienced inclusive education (mainly only experiencing physical inclusive environment without subdivided designed learning experiences for both parties) on a daily basis within the school setting, able-bodied students may have formed the perception that inclusive education is not helpful or beneficial for both parties. Thus, they are likely to believe that having separate educational environments is good for all of them. Hence, students classified as the rationalizing type are likely to have quick conclusions that inclusive education does not work for everyone based on 
their unpleasant personal experiences. They might not even take socially desirable or PC attitudes, because they believe their opposition toward inclusive education is a reflection of very reasonable and rational attitudes without having any discrimination or prejudice toward PWDs. They might insist that they cognitively accept the PWDs as members of our community, but that inclusive education is a poorly designed and unsuccessful education system that does not benefit students with and without disabilities.

Several studies revealed how PWDs still experience distinctive prejudice and discrimination against disability in the recruitment process, workplace, and their daily lives (Baldwin \& Choe, 2014; Dipboye \& Colella, 2013; Stone \& Wright, 2013), despite long-standing disability rights movements and related legislations. Along with the other profiles above, this rationalizing type, which is skeptical about disability and inclusive education, needs to be explored and openly discussed to achieve genuine inclusion of PWDs beyond political agendas.

Regarding anxiety in processing counter-stereotypic information (Wilder \& Shapiro, 1989), the rationalizing type in this study failed to assimilate out-group members (PWDs) into their perceptions. In other words, despite various efforts to include minorities, there were some individuals who felt anxious, isolated, and angry about this social change. Therefore, the presence of the rationalizing type is not diminished and should be further explored to find effective ways to understand and include these individuals.

\section{Potential Proactive Type}

The potential proactive type included $14.12 \%$ of study participants who showed less favorable cognitive-behavioral attitudes toward PWDs, but the highest positive emotion connectedness toward disabilities as well as positive attitudes toward inclusive education. We labeled this group potential proactive, because this population represented a model of pro-disability initiatives. In fact, Korean college students in this study are the first generation of students who experienced full inclusive education in public school settings in the 2000s. Compared to profiles mentioned above, the potential proactive type can be interpreted as the ideal type of individuals the Korean inclusive education movements may intend to target (Kim, 2012, 2013). Having inclusive education with peers with disabilities was likely to be their first learning experience of having some knowledge of persons with disabilities and acquiring some basic skills to interact with them (Kim, 2012, 2013). Thus, by experiencing inclusive education throughout their elementary and secondary school years, current Korean college students are likely to shape their critical conscientiousness, which is a capability to analyze structural contribution to societal inequities, to perceive self-efficacy of societal change, and to act (Freire,
1993; Watts et al., 2011). As they are in the learning trajectory to manage individual and societal stereotypical perceptions, attitudes, and behaviors toward people with disability, they are likely to have relatively below average readiness to expand their social justice competency from the individual (e.g., embracing PWDs as family, peer, and neighbor) to the societal level (e.g., actively support for the societal change for the well-being of PWDs). However, they have feelings of empathy and worth if they can be helpful to PWDs directly or indirectly and are also supportive of the inclusive education system. Thus, the potential proactive type of individuals are likely to be more ready to take small steps to change their ambivalent or slightly negative cognitive perceptions and behaviors by expanding their emotional empathy to cognitive empathy toward PWDs (Decety \& Yoder, 2016). Such a change can also be achieved by increasing their sensitivity to overall injustice for others in addition to their support for inclusive education (Freire, 1993; Watts et al.,2011). From the experiences of inclusive education from their school days, individuals who are categorized in the potential proactive type are likely to go through enhancing their awareness, knowledge, and skills to manage societal injustice issues and to be advocates for underrepresented or marginalized ones, including PWDs.

\section{Implications}

The cultural environments in college campuses have become more complex and challenging for students as they cope with individual differences, such as gender, race, physical ability, income, and age, and handle intolerant experiences of discrimination, stereotype threat, and micro-aggression (Pope et al., 2004; Sue \& Sue, 2008). Thus, college students are in a continuing process of engagement with learning and re-learning to gain social justice competencies (Pope et al., 2004; Watts et al., 2011). Within their curriculum and extracurricular activities in colleges, students are likely to experience difficulties exploring their beliefs about specific multicultural and social justice-related topics, such as disability issues. Thus, both the general public and specialists must develop and increase their social justice competency through the disability-friendly modification of educational programs and curriculum in colleges. Specifically, desires for being PC should be addressed as it infringes on students' opportunities to express and explore their personal beliefs, due to fear of others' perceptions (Ladany et al., 2005). Thus, a supportive environment and atmosphere to openly discuss vibrant and intellectually challenging topics should be formed.

According to the present study's results, planning an intervention to change cognitive-behavioral attitudes toward PWDs is essential. And, when designing an intervention, addressing individuals' discomfort with PWDs related to 
educational systems among the general population should be considered. Given the functional hypothesis of attitudes (Eagly\&Chaiken, 1993; Katz, 1960), we know that attitudes serve different functions for different individuals. Katz (1960) identified four functions of attitudes: (a) utilitarian function, wherein people are motivated to gain rewards or avoid punishments from their environment; (b) knowledge functions to organize and simplify perceptions of a complex and ambiguous environment; (c) ego-defensive function, wherein people use attitudes for defensive mechanisms, such as denial or projection to protect their self-concepts against possible internal or external threats; and (d) valueexpressive function of self-expression or self-actualization. Based on functional theory of attitudes, the discrepancy between the attitudes toward PWDs and the attitudes toward inclusive education could be a reflection of various functions of each attitude, such as acting adequately within society rules (utilitarian function) or a belief that separate environments are good for both groups of people with a denial of one's own prejudice or privileged status based on ableism (an ego-defensive function). Thus, counselors and educators must explore the function of attitudes for college students, as their resulting attitudes could differ individually based on the underlying function and could be changed if the purpose of the function is changed.

In addition, addressing emotions toward PWDs is also necessary. The initial uneasy emotional response or arousal toward PWDs cannot be avoided if it is a natural reaction. However, for students to understand their privilege of being able-bodied and learn what it means to accept and respect differences, providing an opportunity for individuals to express their thought processes about how the initial feelings are interpreted in their minds and an environment where they can increase cognitive empathy and positive feelings with perspective-taking exercises (Decety\& Yoder, 2016) would be necessary and helpful. Several studies reported that empathetic feelings for a person in need increase that person's tendency to help (Batson et al., 2002; Eisenberg \& Miller, 1987). For example, Batson et al. (2002)'s experiments in perspective-taking manipulation of empathy revealed that people induced to feel empathy by reading a scenario reported increased empathic feelings that evoked positive attitudes toward the person which, in turn, increased their willingness to act in a way to benefit the person in need.

In sum, given individuals' differences in experiences with PWDs and inclusive education among the general population, individuals who presented positive attitudes toward inclusive education might not be homogenous. In other words, regarding the positive attitudes toward inclusive education, individuals who present societal attitudes toward PWDs due to the desire to be politically correct are likely to differ from individuals who have positive attitudes toward individuals with disabilities on the basis of their personal experiences. Those who show a discrepancy between social and personal attitudes might care more about how they are perceived by others or might think about disability issues at the abstract level, as they have not openly processed their true feelings and thoughts by frequently socializing with PWDs. Thus, their current positive attitudes toward inclusive education might not accurately represent what they value and believe; they might even feel confused when they experience this discrepancy between their internalized values and their real experiences. Of course, there will be individuals who have strong positive attitudes toward inclusive education via a higher degree of socialization with PWDs. Meanwhile, there will be individuals who are consistent in maintaining negative stereotypical thoughts toward PWDs, having little experience due to a lack of motivation, and having negative attitudes toward inclusive education. The empirical exploration of lay people's possible differences in their societal and personal attitudes toward PWDs and inclusive education would be beneficial in broadening our understanding about people's perceptions about disabilities and inclusive education and in further discussing various ways of addressing this gap.

\section{Limitations and Conclusions}

There are several limitations in our study. First, the current findings cannot be generalized as the sample consisted of Korean college students at three major universities in Seoul. Thus, future studies should be conducted with college students from various ethnic and cultural backgrounds. Second, the results of this study were based on cross-sectional data. Thus, longitudinal research would be beneficial in examining how emotional, cognitive, and behavioral attitudes interact and are influenced and changed. Third, the attitudes toward PWDs and inclusive education were identified via an explicit self-reported survey. This limitation is not particularly uncommon in quantitative research, but measuring implicit attitudes would be beneficial in capturing individuals' stereotypes and biases toward disability and related multicultural issues. Despite these limitations, the current study provided unique and in-depth understanding of individual differences in emotions, thoughts, and behavioral intentions toward PWDs and inclusive education.

Availability of data and material Datasets will be available from the corresponding author at jeji@inha.ac.kr on reasonable request.

Code availability Not applicable

Authors' contributions EJ was involved in designing of the study and collecting data with writing the introduction. SP was involved in analyzing of data and writing the results section. YS was involved in 
conceptualizing and collecting the data with writing the discussion. All authors reviewed and approved the manuscript.

\section{Declarations}

Conflicts of interests The authors declare that they have no competing interests.

Ethics approval All procedures performed in this study involving human participants were in accordance with the ethical standards of the University of Seoul's research committee and with the 1964 Helsinki declaration and its later amendments or comparable ethical standards.

Consent to participate The consent obtained from the study participants is written.

\section{Consent for publication Not applicable}

Open Access This article is licensed under a Creative Commons Attribution 4.0 International License, which permits use, sharing, adaptation, distribution and reproduction in any medium or format, as long as you give appropriate credit to the original author(s) and the source, provide a link to the Creative Commons licence, and indicate if changes were made. The images or other third party material in this article are included in the article's Creative Commons licence, unless indicated otherwise in a credit line to the material. If material is not included in the article's Creative Commons licence and your intended use is not permitted by statutory regulation or exceeds the permitted use, you will need to obtain permission directly from the copyright holder. To view a copy of this licence, visit http://creativecommons.org/licenses/by/4.0/.

\section{References}

Americans with Disabilities Act (1990). Public Law 101-336. 42 U.S.C. 12111, 12112.

American Psychological Association. (2012). Guidelines for assessment of and intervention with persons with disabilities. American Psychologist, 67(1), 43-62. https://doi.org/10.1037/a0025892

Amor, A. M., Hagiwara, M., Shogren, K. A., Thompson, J., Verdugo, M. A., Burke, K. M., \& Aguayo, V. (2019). International perspectives and trends in research on inclusive education: A systematic review. International Journal of Inclusive Education, 23(12), 1277-1295.

Baldwin, M. L., \& Choe, C. (2014). Wage discrimination against workers with sensory disabilities. Industrial Relations: A Journal of Economy and Society, 53(1), 101-124. https://doi.org/10.1111/ irel. 12048

Batson, C. D., Chang, J., Orr, R., \& Rowland, J. (2002). Empathy, attitudes, and action: Can feeling for a member of a stigmatized group motivate one to help the group? Personality and Social Psychology Bulletin, 28, 1656-1666.

Beck, A. T. (1976). Cognitive therapy and the emotional disorders. International Universities Press.

Berlin, K. S., Williams, N. A., \& Parra, G. R. (2014). An introduction to latent variable mixture modeling (part 1): Overview and cross-sectional latent class and latent profile analyses. Journal of Pediatric Psychology, 39(2), 174-187. https://doi.org/10.1093/ jpepsy/jst084

Bohner, G., \& Dickel, N. (2011). Attitudes and attitude change. Annual Review of Psychology, 62, 391-417.
Bernard, M. E. (2009). Dispute irrational beliefs and teach rational beliefs: An interview with Albert Ellis. Journal of Rational-Emotive Cognitive-Behavioral Therapy, 27, 66-67.

Chang, K. S. (2010). South Korea under compressed modernity: Familial political economy in transition. Routledge.

Choi, W. G., \& Park, H. J. (2009). A study of social distance for persons with disabilities. Journal of Disability and Welfare, 10, 69-105.

Code of Federal Regulations. (2008). Title 34, (\$) 300.8 (c), revised as of 2008.

De Boer, A., Pijl, S. J., \& Minnaert, A. (2011). Regular primary schoolteachers' attitudes toward inclusive education: A review of the literature. International Journal of Inclusive Education, 15, 331-353. https://doi.org/10.1080/13603110903030089

Decety, J., \& Yoder, K. J. (2016). Empathy and motivation for justice: cognitive empathy and concern, but not emotional empathy, predict sensitivity to injustice for others. Social Neuroscience, 11(1), 1-14. https://doi.org/https://doi.org/10.1080/17470919.2015. 1029593

Dipboye, R. L., \& Adrienne, C. (2013). Discrimination at work: The psychological and organizational bases. Taylor \& Francis.

Dziak, J. J., Lanza, S. T., \& Tan, X. (2014). Effect size, statistical power, and sample size requirements for the bootstrap likelihood ratio test in latent class analysis. Structural equation modeling a multidisciplinary journal, 21(4), 534-552.

Eagly, A. H., \& Chaiken, S. (1998). Attitude structure and function. In D. Gilbert, S. Fiske, \& G. Lindzey (Eds.), The handbook of social psychology (Vol. 1, 4th ed., pp. 269-322). McGraw-Hill.

Ellis, A. (2006). How to stubbornly refuse to make yourself miserable about anything. Citadel Press.

Ellis, A. (1962). Reason and emotion in psychotherapy. Lyle Stuart.

Eisenberg, N., \& Miller, P. A. (1987). The relation of empathy to prosocial and related behaviors. Psychological Bulletin, 101(1), 91-119.

Fazio, R. H. (2007). Attitudes as object-evaluation associations of varying strength. Social Cognition, 25, 603-637.

Ferguson, D. L. (2008). International trends in inclusive education: The continuing challenge to teach each one and everyone. European Journal of Special Needs Education, 23(2), 109-120.

Foley-Nicpon, M., \& Lee, S. (2012). Disability research in counseling psychology journals: A 20-year content analysis. Journal of Counseling Psychology, 59(3), 392-398.

Freire, P. (1993). Pedagogy of the oppressed. Penguin Books.

Fuchs, D., \& Fuchs, L. S. (1994). Inclusive schools movement and the radicalization of special education reform. Exceptional Children, 60(4), 294-309.

Friend, M., \& Bursuck, W. D. (2002). Including students with special needs: A practical guide for classroom teachers. Pearson Education

Gelso, C. J., Nutt Williams, E., \&Fretz, B. R. (2014). Counseling psychology (3rd ed.). American Psychological Association. https:// doi.org/10.1037/14378-000

Gething, L. (1994). Interaction with disabled persons scale. Journal of Social Behavior and Personality, 9(5), 23-42.

Hailes, H. P., Ceccolini, C. J., Gutowski, E., \& Liang, B. (2021). Ethical guidelines for social justice in psychology. Professional Psychology: Research and Practice, 52(1), 1-11. https://doi.org/10. 1037/pro0000291

Han, S. (2019). The Effect of the Entrepreneurship Education-Based Cafe Activity Club on Career Decision Efficacy and Vocational Readiness of High School Students with Intellectual Disabilities, and on Social Distance of Peers to Students with Intellectual Disabilities. Ewha Women University Master's thesis. Unpublished Manuscript.

Hughes, G. (2011). Political correctness: A history of semantics and culture. John Wiley \& Sons. 
Iacono, T., Tracy, J., Keating, J., \& Brown, T. (2009). The Interaction with Disabled Persons scale: Revisiting its internal consistency and factor structure, and examining item-level properties. Research in Developmental Disabilities, 30, 1490-1501. https:// doi.org/10.1016/j.ridd.2009.07.010

Ji, E., \& Shin, Y. J. (2015). The effect of college students' sense of social distance from people with disabilities on perspectives toward inclusive education: The mediating effects of interactions with people with disabilities. Special Education Research, 14(1), 205-225.

Jung, H. Y., \& Seo, B. S. (2012). A study on pre-service early childhood teachers' social distance from people with disabilities. The Journal of Special Children Education, 14(1), 117-145.

Jung, T., \& Wickrama, K. A. S. (2008). An introduction to latent class growth analysis and growth mixture modeling. Social and Personality Psychology Compass, 2(1), 302-317. https://doi.org/10. 1111/j.1751-9004.2007.00054.x

Kamenetsky, S. B., Dimakos, C., Ashlemand, A., Saleh, A., \& AliMohammed, S. (2016). Eliciting help without pity: The effect of changing media images on perceptions of disability. Journal of Social Work in Disability \& Rehabilitation, 15(1), 1-21. https:// doi.org/10.1080/1536710X.2016.1124251

Katz, D. (1960). The functional approach to the study of attitudes. Public Opinion Quarterly, 24(2), 163-204.

Kim, E., Zhang, J., \& Sun, X. (2019). Comparison of special education in the United States, Korea, and China. International Journal of Special Education, 33(4), 796-814.

Kim, M. (2016). The influence of the inclusive education on non-disabled high school students' experiences and attitudes toward the disabled (Unpublished master's thesis). Yonsei University, South Korea.

Kim, Y.-M. (2013). Inclusive education in Korea: Policy, practice, and challenges. Journal of Policy and Practice in Intellectual Disabilities, 10(2), 79-81. https://doi.org/10.1111/jppi.12034

Kim, Y.-W. (2012). Inclusive education in South Korea. International Journal of Inclusive Education, 18(10), 1-12.

Kim, B. H. (2006). Present situation and problems of inclusive education in Korea: An international comparison study. Japanese Journal of Special Education, 43, 449-457.

Kim, B.-K., \& Park, J. (2017). Effects of Universal Support Implemented as a Part of Grade-wide Positive Behavior Support on Social Competence, Class Participation Behavior, and Perceptions of School Climate in Elementary School Students in Inclusive Classes. Journal of Educational \& Behavioral Disorders, 33(1), 85-105.

Ko, U., Mok, H., \& S. (2013). A study on nondisabled people's sense of social distance from the disabled. Journal of Special Education \& Rehabilitation Science, 52(4), 127-151.

Korea Association for Special Education (2019, April). Current Situation and statistics of Special Education. https://kess.kedi.re.kr/ post $/ 6681285$ ?itemCode $=03 \&$ menuId $=$ m_02_03_03

Ladany, N., Friedlander, M. L., \& Nelson, M. L. (2005). Heightening multicultural awareness: It's never been about political correctness. In N. Ladany, M. L. Friedlander, \& M. Lee (Eds.), Critical events in psychotherapy supervision: An interpersonal approach (pp. 53-77). American Psychological Association.

Li, H., \& Lee, Y.-T. (2011). Incidental emotional states in relation to A-B-C model. Journal of Cognitive and Behavioral Psychotherapies, 11(2), 209-219.

Lo, Y., Mendell, N. R., \& Rubin, D. B. (2001). Testing the number of components in a normal mixture. Biometrika, 88(3), 767-778.

Lubke, G. H., \& Muthén, B. (2005). Investigating population heterogeneity with factor mixture models. Psychological Methods, 10(1), 21-39. https://doi.org/10.1037/1082-989X.10.1.21

McCrae, J. S., Chapman, M. V., \& Christ, S. L. (2006). Profile of children investigated for sexual abuse: Association with psychopathology symptoms and services. American Journal of Orthopsychiatry, 76(4), 468-481. https://doi.org/10.1037/00029432.76.4.468

Magidson, J., \& Vermunt, J. K. (2004). Latent class models. In D. Kaplan (Ed.), Handbook of quantitative methodology for the social sciences (pp. 175-198). Sage.

Magidson, J., \& Vermunt, J. (2002). Latent class models for clustering: A comparison with K-means. Canadian Journal of Marketing Research, 20, 37-44.

Maynard, B. R., Salas-Wright, C. P., Vaughn, M. G., \& Peters, K. E. (2012). Who are truant youth? Examining distinctive profiles of truant youth using latent profile analysis. Journal of Youth and Adolescence, 41, 1671-1684. https://doi.org/10.1007/ s10964-012-9788-1

Mittler, P. (2012). Working toward inclusive education: Social contexts. David Fulton Publishers.

Muthén, L. K., \& Muthén, B. O. (2010). Mplus user's guide. Author.

Nylund, K. L., Asparouhov, T., \& Muthén, B. O. (2007). Deciding on the number of classes in latent class analysis and growth mixture modeling: A Monte Carlo simulation study. Structural Equation Modeling, 14, 535-569. https://doi.org/10.1080/1070551070 1575396

Oh, W. S., Choi, S. K., Lee, H. S., Bae, H., \& I. (2007). Development and applying possibility of testing tools for teachers' attitude on inclusive education. The Journal of Special Education, 8(4), 217-240.

Pastor, D. A., Barron, K. E., Miller, B. J., \& Davis, S. L. (2007). A latent profile analysis of college students' achievement goal orientation. Contemporary Educational Psychology, 32(1), 8-47. https://doi.org/10.1016/j.cedpsych.2006.10.003

Pham, M. T. (2007). Emotion and rationality: a critical review and interpretation of empirical evidence. Review of General Psychology, 11, 155-176.

Piat, M. (2000). The NIMBY phenomenon: Community residents' concerns about housing for deinstitutionalized people. Health \& Social Work, 25, 127-138.

Pope, R. L., Reynold, A. L., \& Mueller, J. A. (2004). Multicultural competence in student affairs. Jossey-Bass.

Spielberger, C. D., Gorsuch, R., \& Lushene, R. (1970). Manual for the state-trait anxiety inventory. Consulting Psychologists Press.

Stone, A., \& Wright, T. (2013). When your face doesn't fit: Employment discrimination against people with facial disfigurements. Journal of Applied Social Psychology, 43(3), 515-526. https:// doi.org/10.1111/j.1559-1816.2013.01032.x

Sue, S. (1999). Science, ethnicity, and bias: Where have we gone wrong? American Psychologist, 54, 1070-1077.

Sue, D. W., \& Sue, D. (2003). Counseling the Culturally Diverse. Theory and Practice. New York: John Wiley \& Sons.

Szymanski, E. M. E., \& Parker, R. M. (2003). Work and disability: Issues and strategies in career development and job placement. Pro-ed.

Townsend, K. C., \& McWhirter, B. T. (2005). Connectedness: A review of the literature with implications for counseling, assessment, and research. Journal of Counseling \& Development, 83, 191.

UNESCO (2016). Reaching out to all learners-A resource pack for supporting inclusion. http://www.ibe.unesco.org/sites/default/files/ resources/ibe-crp-inclusiveeducation-2016_eng.pdf

United States Government Accountability Office Report to Congressional Requesters (2011, October). Gender pay differences: Progress Made, but Women Remain Overrepresented among LowWage Workers. Retrieved from http://www.gao.gov/new.items/ d1210.pdf

Vermunt, J. K., \& Magidson, J. (2002). Latent class cluster analysis. In J. Hagenaars \& A. McCutcheon (Eds.), Applied latent class analysis (pp. 89-106). Cambridge University Press. 
Villa, R. A., Thousand, J. S., Meyers, H., \& Nevin, A. (1996). Teacher and administrator perceptions of heterogeneous education. Exceptional children, 63(1), 29-45.

Watts, R. J., Diemer, M. A., \& Woight, A. M. (2011). Critical consciousness: current status and future direction. New Directions for Child and Adolescent Development, 134, 43-57. https://doi. org/10.1002/cd.310

Wessler, R. L. (1988). Inaccurate implications of philosophy of science and rational-emotive therapy: A reply to DiGiuseppe. Psychotherapy: Theory, Research, Practice. Training, 25(1), 149-153. https://doi.org/10.1037/h0085312

West, S. G., Finch, J. F., \& Curran, P. J. (1995). Structural equation modeling: Concepts, issues and applications. Sage Publications.

Wilder, D. A., \& Shapiro, P. N. (1989). Role of competition-induced anxiety in limiting the beneficial impact of positive behavior by an out-group member. Journal of Personality and Social Psychology, 56(1), 60-69. https://doi.org/10.1037/0022-3514.56.1.60

Will, M. C. (1986). Educational children with learning problems: A shared responsibility. Exceptional Children, 52, 411-416. https:// doi.org/10.1177/001440298605200502
Woo, H., Goo, M., \& Lee, M. (2019). A content analysis of research on disability: American counseling association journals between 2003 and 2013. Journal of Multicultural Counseling and Development, 44(4), 228-244.

World Health Organization (2015, December). Disability and Health. Retrieved fromhttps://www.who.int/en/news-room/fact-sheets/ detail/disability-and-health

Wrightsman, L. S., \& Brigham, J. C. (Eds.). (1973). Contemporary issues in social psychology. Thomson Brooks/Cole.

Publisher's Note Springer Nature remains neutral with regard to jurisdictional claims in published maps and institutional affiliations. 